\title{
Enhanced eBooks in the teaching/learning process of electronics
}

\section{Sánchez-Azqueta, Carlos ${ }^{\mathrm{a}}$; Gimeno, Cecilia ${ }^{\mathrm{b}}$; Celma, Santiago ${ }^{\mathrm{a}}$ and Aldea, Concepción ${ }^{\mathrm{a}}$}

${ }^{\mathrm{a}}$ Group of Electronic Design (GDE-i3A), Universidad de Zaragoza, Spain, ${ }^{\mathrm{b}}$ ICTEAM, Université Catholique de Louvain, Belgium.

\begin{abstract}
Information and communications technologies (ICTs) are an invaluable tool to facilitate and promote meaningful learning. Numerous higher education institutions have already adopted the use of virtual learning environments, incorporating e-learning along with traditional teaching methodologies as part of a mixed learning. M-learning maintains all the advantages of $e$ learning while adding the possibility of learning anywhere and anytime. This work presents an enhanced book in Electronics that contains a set of multimedia resources (images, videos, and apps) that have been specifically created to stimulate an adapted and interactive learning. The material presented in this work has been designed to be downloadable to mobile devices (smartphones and tables) running iOS and Android.
\end{abstract}

Keywords: enhanced eBook, ICT-based learning, m-learning, ubiquitous learning 


\section{Introduction}

Our society is immersed in a transformation process that affects not only scientific and technological aspects, but also other scopes of life. All reflections concerning the future evolution of education must take into account this context, where the presence of information and communication technologies (ICTs) will play a major role in higher education. A teaching based on competencies requires a deep change in the conceptions and common practices of students as well as teachers. ICTs are a powerful tool to facilitate, promote and enhance autonomous learning among students; likewise, they ease the tasks of supervision, guidance and support taken on by the teachers throughout the course, as well as their coordination (Buabeng-Andoh, 2015).

Primary and secondary education levels are playing a major role towards digital literacy, incorporating adapted methodologies and enhanced learning environments (digital blackboards and books, Google sites...) to the classroom. A number of higher education and research institutions have committed to strategies focused on OpenWareCourse (OWC) projects, in which all content is free and can be reused, or podcasting to complement teaching. Even research journals start to offer audio slide galleries of their papers.

Many definitions of m-learning and its main features can be found in the literature (Kearney, 2012), as well as surveys on its burst into the current education scene (COL, 2014; SCOPEO, 2011), which coincide in pointing out that the rapid adoption of $\mathrm{m}$ learning strategies comes as a consequence of the wide spread of mobile devices, which allows extending the e-learning paradigm to achieve ubiquitous learning (Pu, 2011). Mlearning, however, does not come without challenges, which arise mainly from the fragmentation that exists among mobile devices and media formats, and the fact that mobile learners are constantly changing the context in which they learn.

Today's mobile devices incorporate numerous advanced apps that endow them with features such as always-on connectivity, geo-localization, ability to record and create contents, among many others, which makes them ideal for ubiquitous learning. Several recent surveys on higher education point out that mobile devices will play a pivotal role in new teaching paradigms (COL, 2014; SCOPEO, 2011; Horizon Project, 2012). Nevertheless, only a few m-learning experiences are to be found for the teaching of science (Zydney, 2015), and in particular for higher education (Cheon, 2012; Motiwalla, 2007).

This work is part of the development of a set of activities oriented to improve the teaching of Electronics in the context of a Degree in Physics. In particular, a complementary educational resource, an enhanced eBook (OECD, 2012), has been elaborated to contribute the intrinsic advantages of m-learning as the first step towards a more ambitious project that will encompass the development of a set of specific apps for mobile devices. This innovation activity and its outcomes are intended to become the starting point of an 
education research process based on an adequate and systematic assessment of the quality of education.

\section{Project}

This work is a continuation of a series of education innovation experiences that have resulted in the creation of a virtual learning environment with a specific data-base in the field of Microelectronics. The goal of this work is the design of a digital book, written in an open-code format that includes multimedia resources (video, audio, interconnectivity and advanced browsing) for its use in mobile devices. All the multimedia content included is intended to strengthen knowledge, delve into key concepts and show real-life applications. Different formats are chosen (podcasts, infographics, hyperlinks and interactive activities) so that they have platform compatibility and are size-optimized.

To provide this teaching resource with a character common to different courses in scientific and engineering degrees, the enhanced eBook deals with general concepts involved in several courses related to electronics and circuits. In particular, this first stage of the project has been developed around the main topics of the study of the MOS transistor.
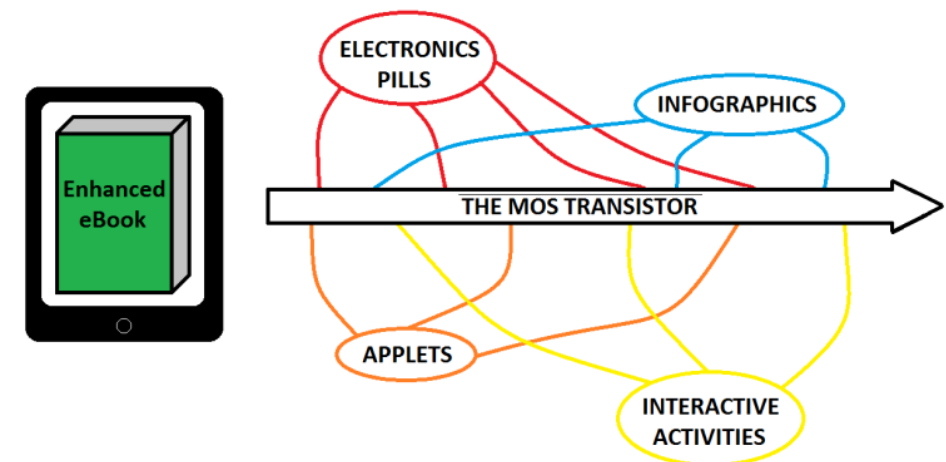

Figure 1. The enhanced eBook and how the enhanced contents appear in the learning process of the student.

The enhanced eBook acts as a conducting thread for the presentation of the topics in the course, and allows the appearance of the enhanced contents when they have their most pedagogical effectivity. This is illustrated in Fig. 1, where the theoretical description of the MOS transistor is given using a classical cumulative approach, but where the various enhanced contents are placed at specific points to illustrate, clarify, or even evaluate the progress of the students. 


\subsection{Enhanced contents:}

The following paragraphs detail some of the resources used to build the enhanced eBook.

Electronics pills. They are a set of tutorials formatted as podcasts. They last for a maximum of five minutes and serve to present contents oriented to going into detail in certain concepts or to stress their links to other courses. They are based in the Digital Learning Object (DLO) model and therefore they must: facilitate the user's learning, be self-contained, and allow a modular integration with ascending hierarchy, this is, allow their integration with other objects to create a more complex one. Electronics pills are widely used as a means to summarise the most relevant concepts of a course and to facilitate the understanding of those aspects of the course that students find the most difficult (Ponce, 2012; Juanes, 2012; Maceiras, 2010).

For example an electronic pill about the MOS transistor is developed explaining its structure (gate, drain, etc.), how it is fabricated in a standard technology process and technical aspects such as its electrostatic properties or the backgate effect.

Infographics. They are a combination of visual materials that provide a graphical display of information. They are mainly used to deliver complex topics by a visual representation that synthesizes or clarifies, making their study more enjoyable (Clarín, 1997). As an educational resource, it is more concise than videos and more narrative than a diagram, allowing a pleasant visualization of information and facilitating the understanding of the most complex concepts. Nevertheless, despite their advantages, infographics are not always the most adequate resource and a careful study of which topics might be delivered using them is required. Also, the creation of infographics is not an easy task, requiring a solid knowledge not only of the concepts that are to be displayed, but also of the specific tools used for their creation.

A number of much elaborated infographics can be found in the Internet (Smithonian, SINC, BBC, La Vanguardia, etc) that deal with topics related to science and technology, but not specific for the study of electronics. For this project, a set of infographics have been created that present the MOS transistor, and its operation and fabrication process, aiming to provide a new form of understanding that does not overlap with the contents of the written materials.

Applets. A set of Matlab interactive applications (Applets) have been adapted from (Dimitrijev, 2000). They integrated areas that constitute the core of one of the topics developed in the enhanced eBook, the MOS transistor. The objective in this case is to facilitate the understanding of the physical phenomena that are involved in the fabrication and operation of electronic devices by a visual description that complements the analytic description that is typically given to students. In particular, the specific realizations are the 
following: (1) fabrication of integrated circuits, (2) semiconductor physics and (3) semiconductor devices.

Interactive activities. A set of interactive activities in the form of short questionnaires has been put in place to provide students with a tool to obtain immediate feedback on their learning process that fosters their metacognitive skills (Evans, 2013). The questionnaires contain statements about the concepts presented in the different resources used to enhance the text.

\section{Results}

To validate the benefits of the enhanced eBook on the learning process, the grades obtained by the students that attended the courses in the previous academic year, when the enhanced eBook was not available, will be compared to the grades obtained by students in the academic year of the implantation of the new tool.

A set of activities has been created to assess the impact of the activity on the learning of students. These activities are characterized by the fact that for their resolution it is advisable to use the resources provided to the students. Among the learning outcomes to be assessed the authors highlight the improvement of the experimental treatment of the theoretical concepts presented in the enhanced eBook, and the results of a test on the topics dealt with in the interactive activities. In particular, three learning outcomes have been analyzed: the characterization of the basic properties of electron transport in semiconductors, the derivation of incremental device models in a small region of operation, and the analysis of the performance of small-signal amplifier configurations.

One of the goals of this innovation activity is that it becomes the starting point of a process of education research. To this end, the procedure to adopt the enhanced eBook throughout all courses in the area will need to be analysed, focusing on learning the main features concerning both the adaptation of the contents and the usability of the enhanced eBooks that the students value the most.

One of the most commonly used techniques to assess and evaluate in the field of technological products and information is based on the user experience (Hassan, 2006). Its formal definition entails several variables: easy of learning (learnability), efficiency, ability to be remembered (memorability), efficacy, and satisfaction. Taking these characteristics as a basis, usability can be measured and assessed, therefore facilitating an improvement in the experience of the final user.

The objective, thus, is to carry out both a longitudinal and a transverse follow-up program. Qualitative as well as quantitative techniques will be put into practice in the process of data 
sampling. Because this is the first year that it is being performed, however, it has to be noted that the interpretation of the data might be slanting.

\subsection{Student feedback.}

Several works propose that students' motivation and satisfaction are highly related with the success of the e-learning process as it is associated with student achievement (Regueras, 2009). Information about the learning process will be obtained by a survey in which a set of statements about the impact of the proposed activity will be presented to the students, who will be asked to indicate their level of agreement. Among the aspects of interest of the use of the enhanced eBooks that will be investigated in the survey, it will be inquired whether they:

- $\quad$ Are easy to use

- Present relevant information

- Foster the acquisition of knowledge

- Allow a more efficient use of time than traditional class notes

Finally, to assess the usability of the enhanced eBooks, a quantitative survey on the time that every student has on average spent using the different resources, such as browsing through the internet for information using the hyperlinks, watching videos and infographics, taking notes, or solving exercises will be carried out, which will allow a comparison to the amount of time typically spent if a similar resource is not available.

Because this activity is now being developed for the first time, no results are available at time of writing this paper; nevertheless, it is expected that they will be ready for their presentation at the conference.

\section{Conclusions}

Along with the benefits derived from m-learning (immediate access, interaction, diversity and customization and individualization of learning), and the advantages of enhanced eBooks, in which the text serves as a guide though its various functionalities to facilitate the interaction between the reader and the book itself, a greater autonomy of the student can be achieved, which helps to develop transverse competencies such as time management, and self-organization, fostered by the no-linearity of the reading in this format.

The teachers expect that the application of the methodology proposed in this work will enhance the understanding of the physics behind the operation of semiconductor devices thanks to the introduction of a visual description complementary to the traditional analytical approach, thus contributing a deeper understanding of these processes. 


\section{References}

Buabeng-Andoh C., (2015). Factors influencing teachers' adoption and integration of information and communication technology into teaching: A review of the literature, International Journal of Education and Development using Information and Communication Technology (IJEDICT), 8(1), 136-155.

Cheon, J. (2012). An investigation of mobile learning readiness in higher education based on the theory of planned behavior, Computers \& Education 59, 1054-1064.

Clarín (1997). Manual de estilo, 125.

COL (2014). Increasing Access through Mobile Learning, Published by Commonwealth of Learning and Athabasca University.

Dimitrijev, S. (2000). Understanding Semiconductor Devices (The Oxford Series in Electrical and Computer Engineering), Oxford University Press.

Evans, C. (2013). Making sense of assessment feedback in higher education, Review of Educational Research, 83(1), 70-120.

Hassan-Montero, Y. (2006). Factores del diseño web orientado a la satisfacción y nofrustración de uso, Revista Española de Documentación Científica, 29(2), 239-257. Available: http://redc.revistas.csic.es/index.php/redc/article/viewFile/291/353.

Horizont Proyect (2012). Perspectivas Tecnológicas: Educación Superior en Iberoamérica 2012-2017, ISBN 978-0-9846601-9-3.

Juanes, J.A., Prats, A., Alvarez, H., García, B., Rodríguez, M.J. (2012). Técnicas de borrado digital para la creación de sets virtuales de aprendizaje, VII Congreso Internacional de Docencia Universitaria e Innovación.

Maceiras, R., Cancela, A., Goyanes, V. (2010). Aplicación de nuevas tecnologías en la docencia universitaria. Formación Universitaria, 3. Available : http://www.scielo.cl/scielo.php?pid=S0718-50062010000100004\&script=sci_arttext.

Motiwalla, F. M. Mobile learning (2007). A framework and evaluation, Computers \& Education 49, 581-596.

OECD, (2012). E-books: Developments and policy considerations, OECD Digital Economy Papers 208, Available: http://dx.doi.org/10.1787/5k912zxg5svh-en.

Ponce, D., Aguaded, J.I., (2012). iTune Uhu: Fundamentación y propuesta de implantación de contenidos audiovisuales educacionales en la enseñanza universitaria. Actas del IV Congreso Internacional sobre Aplicación de Tecnologías de la Información y Comunicaciones Avanzadas (ATICA2012), 255-262.

$\mathrm{Pu}$, H., Lin, J., Song, Y., and Liu, F. (2011). Adaptive device context based mobile learning systems, International Journal of Distance Education Technologies (IJDET), 9(1), 4456.

Regueras, L. M., Verdú, E., Munoz, M. F., Perez, M.A. ,de Castro, J.P. and Verdú, M.J., (2009). Effects of competitive e-learning tools on higher education students: A case study, IEEE Transactions on Education, 52(2), 279 - 285.

SCOPEO, (2011). M-learning en España, Portugal y América Latina, SCOPEO. 
Kearney, M., Schuck, S., Burden, K., Aubusson, P., (2012). Viewing mobile learning from a pedagogical perspective, Research in Learning Technology, 20, 14406, Available: http://journals.co-action.net/index.php/rlt/article/view/14406.

Zydney, J. M., (2015). Mobile apps for science learning: Review of research, Computers \& Education. 